\title{
Minimally invasive plate osteosynthesis vs conventional fixation techniques for surgically treated humeral shaft fractures: a meta-analysis
}

\author{
Xuqi Hu ${ }^{1}$, Siqi Xu², Huigen Lu', Bao Chen ${ }^{1}$, Xiao Zhou ${ }^{1}$, Xiaojun He${ }^{1}$, Jiaping Dai ${ }^{1}$, Zhongwei Zhang ${ }^{1}$ \\ and Suiliang Gong ${ }^{1 *}$
}

\begin{abstract}
Background: In this study, we performed a meta-analysis to identify whether minimally invasive plate osteosynthesis (MIPO) was superior to conventional fixation techniques (CFT) for treating humeral shaft fractures.

Methods: A systematic literature search was conducted up to February 2016 in ScienceDirect, Springer, MEDLINE, and PubMed databases for relevant papers that compared the outcomes of MIPO with CFT, such as open reduction with plate osteosynthesis (ORPO) and intramedullary nail (IMN) for treating humeral shaft fractures. Meta-analysis was performed with Review Manager 5.0 software.

Results: According to the search strategy, eight studies that covered 391 patients were enrolled, including four randomized controlled trials (RCTs), two prospective cohort trials, and two retrospective cohort trials. Our meta-analysis did not detect any significant difference between MIPO and CFT (IMN and ORPO) in terms of operative time, fracture union rate, and fracture union time. However, MIPO has a less rate of complications and iatrogenic radial nerve palsy than that of ORPO and higher adjacent joint function scores than those of IMN $(p<0.05)$.
\end{abstract}

Conclusions: Based on the present evidence, this meta-analysis suggested that MIPO was a better choice for treating humeral shaft fractures than CFT. However, more high-quality randomized trials are still needed to further confirm this conclusion in the future.

Keywords: Minimally invasive plate osteosynthesis, Open reduction with plate osteosynthesis, Intramedullary nail, Humeral shaft fracture, Meta-analysis

\section{Background}

Fractures of humeral shaft are common injuries, which make up 1 to $3 \%$ of all fractures [1-5]. Historically, nonoperative treatment has been widely used for these injuries. However, a high rate of nonunion was reported in humeral shaft fracture patients with functional bracing $[6,7]$. Therefore, many orthopedic surgeons tend to prefer operative treatment for humeral shaft fractures.

Three main operative techniques have been developed for treating displaced humeral shaft fractures.

\footnotetext{
* Correspondence: jxhuxuqi@163.com

'Department of Orthopaedics, the Second Affiliated Hospital of Jiaxing

University, 1518 Huancheng North Road, Jiaxing, China

Full list of author information is available at the end of the article
}

Intramedullary nail and plate are the conventionally used surgical methods [5, 8]. Currently, open reduction and plate fixation remains to be the golden standard for humeral shaft fractures $[9,10]$. Recently, minimally invasive plate osteosynthesis (MIPO) techniques with encouraging results in humeral shaft fracture patients have been reported [11-14]. This technique has advantages of less soft tissue dissection, a high rate of union, low risks of infection, and no need for radial nerve exposure [15]. It seems to imply that MIPO is superior to conventional fixation techniques (CFT), such as open reduction with plate osteosynthesis (ORPO) and intramedullary nail (IMN).

Recently, several randomized controlled trials (RCTs) and comparative clinical studies have been conducted to 
compare MIPO with CFT for treating humeral shaft fractures. In this study, we performed a meta-analysis to identify whether MIPO was superior to CFT for treating humeral shaft fractures.

\section{Methods}

\section{Search strategy}

Since there were only a small amount of relevant RCTs in the literature, observational studies were also included. A systematic literature search was conducted up to February 2016 in ScienceDirect, Springer, MEDLINE, and PubMed databases. We screened the title and abstract with key words as follows: "minimally invasive plate osteosynthesis" or "MIPO", "plate" or "plating", "intramedullary nail" or "intramedullary pin", and "humeral shaft fracture" or "fracture of humeral shaft". In addition, references of the selected articles and relevant review papers were also searched. Unpublished data were not reviewed. The language of articles was limited to English.

\section{Inclusion and exclusion criteria}

The following eligibility criteria were applied in selecting articles: (1) RCTs or observational studies that compared the clinical and/or radiological outcomes of MIPO with CFT for treating humeral shaft fractures; (2) totally followed patients had to be more than 30 ; and (3) skeletally mature patients. The exclusion criteria included the following: (1) a pathologic fracture; (2) studies that did not report the outcome of interest; and (3) repeated studies or reviews. Two people independently performed the selection of studies. Any disagreement between the reviewers was resolved by consensus with a third reviewer.

\section{Data extraction}

Two reviewers extracted data independently based on the following categories: (1) basic characteristics, such as study design, published year, study population characteristics, and humeral shaft fracture type; (2) primary outcomes, consisting of postoperative clinical function evaluated by the University of California, Los Angeles (UCLA) Shoulder Scale [16] and Mayo Elbow performance score (MEPS) [17]; and (3) secondary outcomes, such as complications and iatrogenic radial nerve palsy, operative time, radiation exposure time, and fracture union time. Any disagreement between the reviewers was resolved by consensus with a third reviewer.

\section{Risk of bias assessment}

To assess the risk of bias of the included RCTs, the Cochrane Handbook for Systematic Reviews of Interventions was applied. The risk of bias of the included observational studies was evaluated with the NewcastleOttawa Scale, and the trials with a total score over 5 were considered to be of high quality [18].

\section{Statistical analysis}

Meta-analysis was performed using Review Manager 5.0 software (Cochrane Collaboration, Oxford, UK). Weighted mean difference (WMD) or standard mean difference (SMD) was calculated for continuous outcomes and risk ratios (RR) for binary outcomes, along with $95 \%$ confidence intervals (CIs). The level of significance was set at $p<0.05$. Heterogeneity was evaluated using the $X^{2}$ test and $I^{2}$ statistics. (Heterogeneity was detected when $p<0.10$ or $I^{2}>50 \%$.) Fixed-effects models were applied unless statistical heterogeneity was significant, in which case random-effects models were used. Standard deviation (SD) was estimated according to the method described by the Cochrane Handbook for Systematic Reviews of Interventions when it was not available. In this paper, CFT was consisted of ORPO and IMN. Then, we conducted subgroup analyses based on the two kinds of CFT (ORPO subgroup and IMN subgroup).

\section{Results}

\section{Literature search}

According to the search strategy, 1026 articles were identified initially, of which 421 were screened after removal of duplicated records. Then, 577 studies were excluded due to inappropriate topics. The full text of the remaining 28 papers were obtained and assessed for eligibility. Twenty of them were further removed according to predefined inclusion/exclusion criteria. Finally, four randomized controlled trials, two prospective cohort studies, and two retrospective cohort trials were enrolled in this study (Fig. 1).

\section{Study characteristics}

The basic information of the eight included studies is shown in Table 1. These studies were published from 2010 to 2015, including four RCTs [19-22], two prospective cohort trials $[23,24]$, and two retrospective cohort trials $[25,26]$. Patients with open fracture or radial nerve injury were excluded in five trials [19, 22, 24-26]. Two studies included patients with radial nerve injury but excluded Gustilo-Anderson [27] III open fractures $[21,23]$. One paper excluded Gustilo-Anderson open fractures [27] classified IIIb or IIIa and patients with radial nerve injury [20]. A total of 391 patients were evaluated which covered 196 patients in the MIPO group and 195 patients in the CFT group. There were three papers comparing MIPO with IMN $[19,20,26]$ and five papers comparing MIPO with ORPO [21-25]. Among 196 patients treated by MIPO, 60 patients were compared with 61 patients treated by IMN and 136 patients were compared with 134 patients treated by ORPO. 


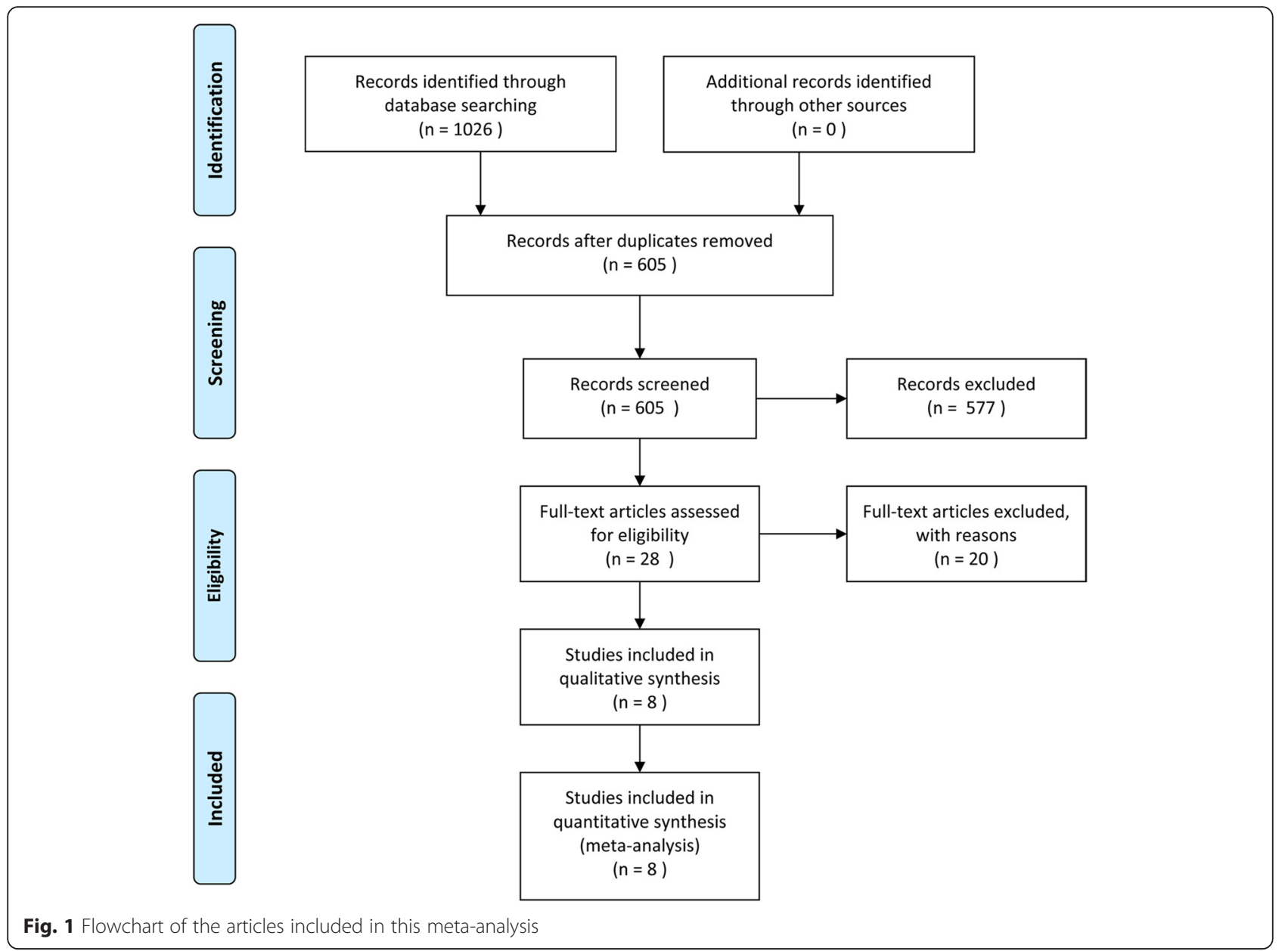

Table 1 Characteristics of the eight included trials

\begin{tabular}{|c|c|c|c|c|c|c|c|c|}
\hline Characteristic & An & $A n$ & Oh & Lian & Benegas & Wang & Kim & Esmailiejah \\
\hline Publication year & 2010 & 2012 & 2012 & 2013 & 2014 & 2015 & 2015 & 2015 \\
\hline Study design & Retro & Retro & Pro & $\mathrm{RCT}$ & RCT & Pro & $\mathrm{RCT}$ & $\mathrm{RCT}$ \\
\hline No. of enrolled patients (MIPO vs CFT) & $17: 16$ & $15: 19$ & $29: 30$ & $24: 23$ & $21: 19$ & $26: 27$ & $36: 36$ & $33: 35$ \\
\hline No. of followed patients (MIPO vs CFT) & $17: 16$ & $15: 19$ & $29: 30$ & $24: 23$ & $21: 19$ & $22: 23$ & $36: 32$ & $32: 33$ \\
\hline Follow-up rate (\%; MIPO vs CFT) & 100:100 & $100: 100$ & 100:100 & 100:100 & 100:100 & $84.6: 85.2$ & $100: 88.9$ & $97.0: 94.3$ \\
\hline $\begin{array}{l}\text { Mean follow-up time (months; MIPO vs } \\
\text { CFT) }\end{array}$ & 25.94:32.88 & $24.2: 20.5$ & 18:22 & 14:15 & $12: 12$ & $12: 12$ & 15 & N/A \\
\hline Mean age (years; MIPO vs CFT) & 37.59:36.93 & 34.4:39.6 & $39.6: 42$ & $38.8: 37.6$ & $44.8: 38.4$ & 39.3:35.7 & $40.6: 44.4$ & $33.4: 34.6$ \\
\hline Gender (\% male; MIPO vs CFT) & $70.6: 56.3$ & 73.3:63.2 & $55.2: 53.3$ & $62.5: 69.6$ & $57.1: 73.7$ & 63.6:69.6 & $52.8: 56.3$ & $75: 72.7$ \\
\hline $\begin{array}{l}\text { Fracture location (proximal/middle/distal; } \\
\text { MIPO vs CFT) }\end{array}$ & $\begin{array}{l}0 / 8 / 9: 0 / 9 / \\
7\end{array}$ & $\begin{array}{l}\text { 0/15/0:0/ } \\
19 / 0\end{array}$ & $\begin{array}{l}6 / 18 / 5: 5 / \\
20 / 5\end{array}$ & $\begin{array}{l}0 / 24 / 0: 0 / \\
23 / 0\end{array}$ & N/A & $\begin{array}{l}4 / 13 / 5: 2 / \\
15 / 6\end{array}$ & $\begin{array}{l}4 / 21 / 11: 4 / \\
16 / 12\end{array}$ & N/A \\
\hline Fracture classification* (A/B/C; MIPO vs CFT) & N/A & $\begin{array}{l}6 / 7 / 2: 10 / \\
8 / 1\end{array}$ & $\begin{array}{l}11 / 11 / 7: 15 / \\
8 / 7\end{array}$ & $\begin{array}{l}9 / 9 / 5: 8 / \\
12 / 2\end{array}$ & $\begin{array}{l}12 / 7 / 2: 9 / \\
4 / 6\end{array}$ & $\begin{array}{l}5 / 8 / 9: 5 / \\
12 / 6\end{array}$ & $\begin{array}{l}19 / 17 / 0: 21 / \\
11 / 0\end{array}$ & $\begin{array}{l}\text { 10/9/13:12/ } \\
10 / 11\end{array}$ \\
\hline Intervention (MIPO vs CFT) & $\begin{array}{l}\text { DCP vs } \\
\text { DCP }\end{array}$ & $\begin{array}{l}\text { DCP vs } \\
\text { IMN }\end{array}$ & LCP vs LCP & $\begin{array}{l}\text { DCP vs } \\
\text { IMN }\end{array}$ & $\begin{array}{l}\text { DCP vs } \\
\text { IMN }\end{array}$ & $\begin{array}{l}\text { LCP vs } \\
\text { LCP }\end{array}$ & LCP vs LCP & DCP vs DCP \\
\hline
\end{tabular}

$R C T$ randomized controlled trial, Retro retrospective cohort study, Pro prospective cohort study, MIPO minimally invasive plate osteosynthesis, CFT conventional fixation techniques, N/A not available, DCP dynamic compression plate, LCP locking compression plate, IMN intramedullary nail. * AO/OTA classification 


\section{Risk of bias assessment}

The risk of bias assessment of the four included RCTs is shown in Table 2. All the RCTs described adequate methods of random sequence generation [19-22]. However, only one paper described allocation concealment [20]. All trials were reported as high risk since it was impossible to perform blinding of participants and personnel. We regarded these studies as low risk of incomplete outcome data addressed because only seven patients lost to follow-up. All of the included RCTs provided the outcomes in detail. The risk of bias of the included cohort trials evaluated with the NewcastleOttawa Scale is demonstrated in Table 3. All these cohort trials had a score over 5 .

\section{Postoperative clinical function (UCLA, MEPS)}

Shoulder function was assessed using the UCLA score in six studies [20-23, 25, 26]. Among these studies, four papers were correlated to the ORPO subgroup [21-23, 25] and others were correlated to the IMN subgroup [20,26]. Meta-analysis showed no significant difference in the ORPO subgroup (WMD $=-0.32,95 \%$ CI $-1.40-0.75$, $\left.p=0.56 ; I^{2}=89 \% ; p<0.01\right)$ or the IMN subgroup $\left(\mathrm{WMD}=1.87,95 \%\right.$ CI $0.02-3.71, p=0.05 ; I^{2}=30 \%$; $p=0.23$ ). Pool analysis of all studies also did not reveal any significant difference between the MIPO group and the CFT group for the UCLA score $\left(\mathrm{WMD}=0.16,95 \%\right.$ CI $-0.91-1.22, p=0.77 ; I^{2}=88 \%$; $p<0.01$ ) (Fig. 2).

MEPS was applied to evaluate elbow function in six studies [19, 21-23, 25, 26]. Among these studies, four papers were correlated to the ORPO subgroup [21-23, 25 ] and the other two papers were correlated to the IMN subgroup [19, 26]. Meta-analysis showed that MEPS was significantly higher in the MIPO group than in the IMN group (WMD = 3.5, $95 \%$ CI 1.53-5.47; $p=$ 0.0005). There was no significant difference between the two arms either in the ORPO subgroup (WMD $=0.42$, $95 \%$ CI $\left.-0.11-0.95, p=0.12 ; I^{2}=0 \% ; p=0.62\right)$ or in the total studies (WMD $=0.82,95 \% \mathrm{CI}-0.47-2.11, p=0.21$; $\left.I^{2}=62 \% ; p=0.03\right)($ Fig. 2).

\section{Complications and iatrogenic radial nerve palsy}

All of the included studies reported the outcome of complications. The pooled data demonstrated a higher complication rate in the CFT group than in the MIPO group (RR $=0.35,95 \%$ CI $0.19-0.66, p=0.001 ; I^{2}=0 \%$; $p=0.62$ ). Subgroup analysis showed that the complication rate in ORPO was significantly higher than that in MIPO (RR $=0.24,95 \%$ CI 0.11-0.55, $p=0.0007 ; I^{2}=$ $0 \% ; p=0.59$ ). However, no significant difference was detected in the IMN subgroup ( $R R=0.66,95 \%$ CI $0.24-$ 1.76, $p=0.40 ; I^{2}=0 \% ; p=0.62$ ) (Fig. 3).

Iatrogenic radial nerve palsy was also available in all of the included papers. Meta-analysis showed that the rate of iatrogenic radial nerve palsy was significantly higher in the CFT group than that in the MIPO group ( $R R=0.25,95 \%$ CI $0.09-0.69, p=0.007 ; I^{2}=0 \% ; p=0.86$ ). Subgroup analysis also detected a significant difference between MIPO and ORPO (RR $=0.24,95 \%$ CI $0.08-0.74, p=0.01$; $\left.I^{2}=0 \% ; p=0.75\right)$. However, subgroup analysis did not reveal any significant difference between MIPO and IMN $(\mathrm{RR}=0.29,95 \% \mathrm{CI} 0.03-3.01, p=0.30)$ (Fig. 3).

\section{Fracture union rate and union time}

Data regarding fracture union was reported in all of the included studies. No significant difference was detected either in the ORPO subgroup $(R R=1.17$, $95 \%$ CI $\left.0.40-3.45, p=0.77 ; I^{2}=8 \% ; p=0.35\right)$ or in the IMN subgroup ( $R R=3.30,95 \%$ CI $0.33-33.05$, $\left.p=0.31 ; I^{2}=0 \% ; p=0.96\right)$. Moreover, the pooled estimate also showed no significant difference between the MIPO group and the CFT group $(\mathrm{RR}=1.45$, $95 \%$ CI $0.55-3.78, \quad p=0.45 ; \quad I^{2}=0 \% ; p=0.58$ ) (Fig. 4).

Fracture union time was available in six trials [19, 21-23, 25, 26]. Four papers were correlated to the ORPO subgroup [21-23,25], and the other two were correlated to the IMN subgroup $[19,26]$. When all studies were considered, meta-analysis did not find any significant difference between the MIPO and CFT groups (WMD $=-0.22,95 \% \mathrm{CI}-0.41-0.97, p=$ $\left.0.72 ; I^{2}=59 \% ; p=0.03\right)$. Subgroup analysis also did not detect any significant difference in the ORPO

Table 2 Risk of bias assessment of randomized controlled trials

\begin{tabular}{lllll}
\hline Risk of bias assessment & Lian 2013 [19] & Benegas 2014 [20] & Kim 2015 [21] & Esmailiejah 2015 [22] \\
\hline Random sequence generation & Low & Low & Low & Low \\
Allocation concealment & Unclear & Low & Unclear & Unclear \\
Blinding of participants and personnel & High & High & High & High \\
Blinding of outcome assessment & Unclear & Low & Low & Unclear \\
Incomplete outcome data addressed & Low & Low & Low & Low \\
Selective reporting & Low & Low & Unclear & Low Unclear \\
Other bias & Unclear & Unclear & & U
\end{tabular}


Table 3 The Newcastle-Ottawa scale score of case control study/cohort study

\begin{tabular}{lllll}
\hline Study ID & Selection & Comparability & $\begin{array}{l}\text { Outcome/ } \\
\text { exposure }\end{array}$ & $\begin{array}{l}\text { Total } \\
\text { score }\end{array}$ \\
\hline An 2010 [25] & 3 & 2 & 3 & 8 \\
An 2012 & 3 & 1 & 3 & 7 \\
Oh 2012 [23] & 4 & 2 & 2 & 8 \\
Wang 2015 & 4 & 2 & 3 & 9 \\
[24] & & & & \\
\hline
\end{tabular}

subgroup (WMD $=-1.91,95 \%$ CI $-5.15-1.32 p=$ $\left.0.25 ; I^{2}=75 \% ; p=0.008\right)$ or the IMN subgroup $\left(\mathrm{WMD}=0.36,95 \% \mathrm{CI}-0.53-1.26, p=0.43 ; I^{2}=0 \%\right.$; $p=0.64)$ (Fig. 4).

\section{Operative time and radiation exposure time}

Seven studies reported the data of operative time [19, 2126]. Subgroup analysis also did not find any significant difference in the ORPO subgroup (WMD $=-7.41,95 \%$ CI $\left.-21.54-6.73, p=0.30 ; I^{2}=64 \% ; p=0.02\right)$ or in the
IMN subgroup (WMD $=-4.87,95 \%$ CI $-58.05-48.30$, $\left.p=0.86 ; I^{2}=95 \% ; p<0.01\right)$. Meta-analysis of total data revealed that the difference was not statistically significant between the MIPO group and the CFT group (WMD $=-8.66$, $95 \%$ CI $-25.61-8.29, p=0.32$; $I^{2}=88 \% ; p<0.01$ ) (Fig. 5).

Since fluoroscopy was not applied in the ORPO subgroup, two paper correlated to the IMN group provided the data of radiation exposure time during surgery [19, 20]. Pooled analysis did not detect any significant difference between IMN and MIPO (WMD = -16.35, $95 \%$ CI -95.0862.39, $p=0.68 ; I^{2}=82 \% ; p=0.02$ ) (Fig. 5).

\section{Discussion}

Although ORPO remains the main standard of operative fixation for humeral shaft fractures, this technique has certain disadvantages of extensive incision, increased incidence of iatrogenic radial nerve palsy, high risk of infection, and violation of the fracture site blood supply $[3,5,10]$. Therefore, in consideration of ORPO, IMN, and MIPO, no consensus has been reached on

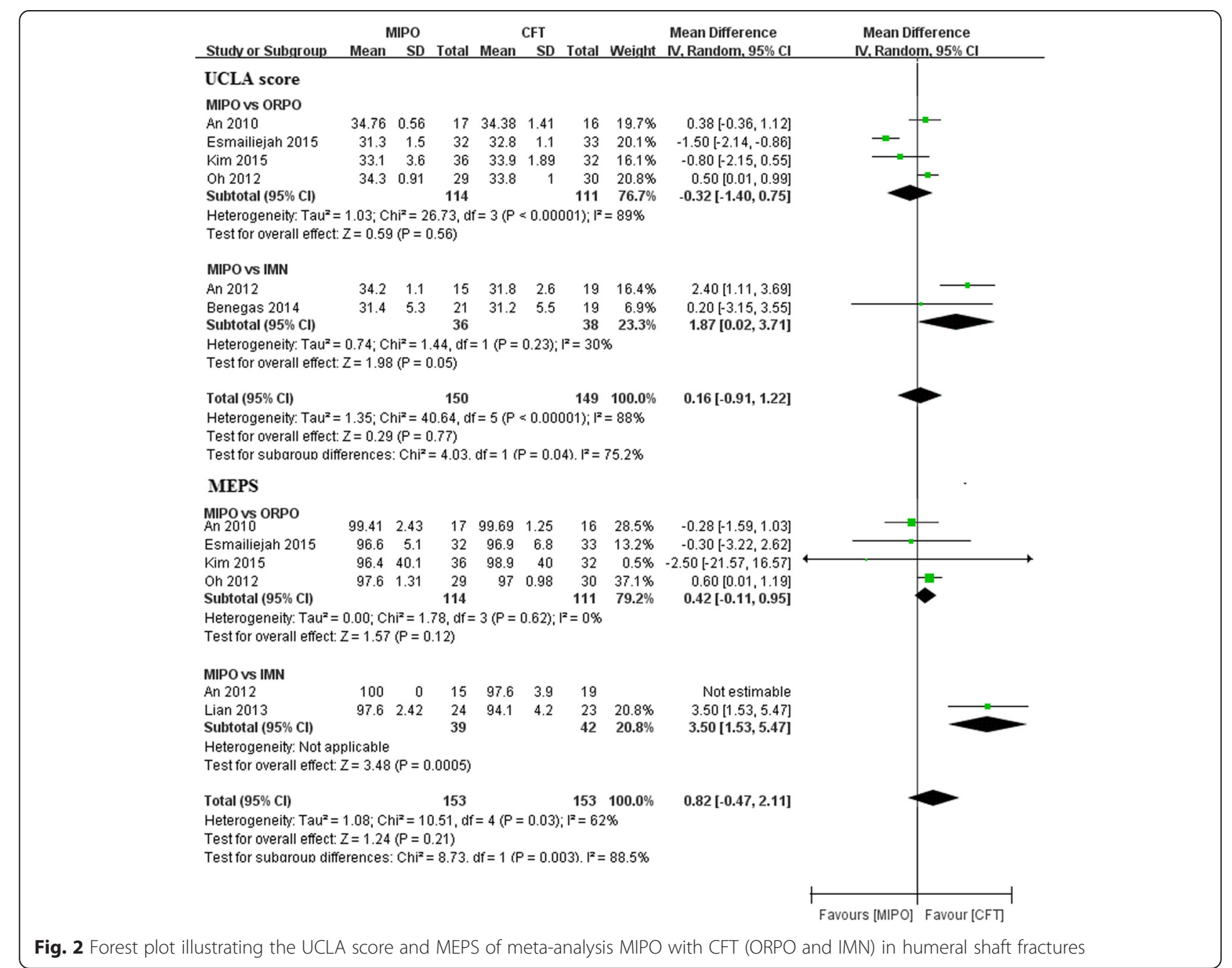




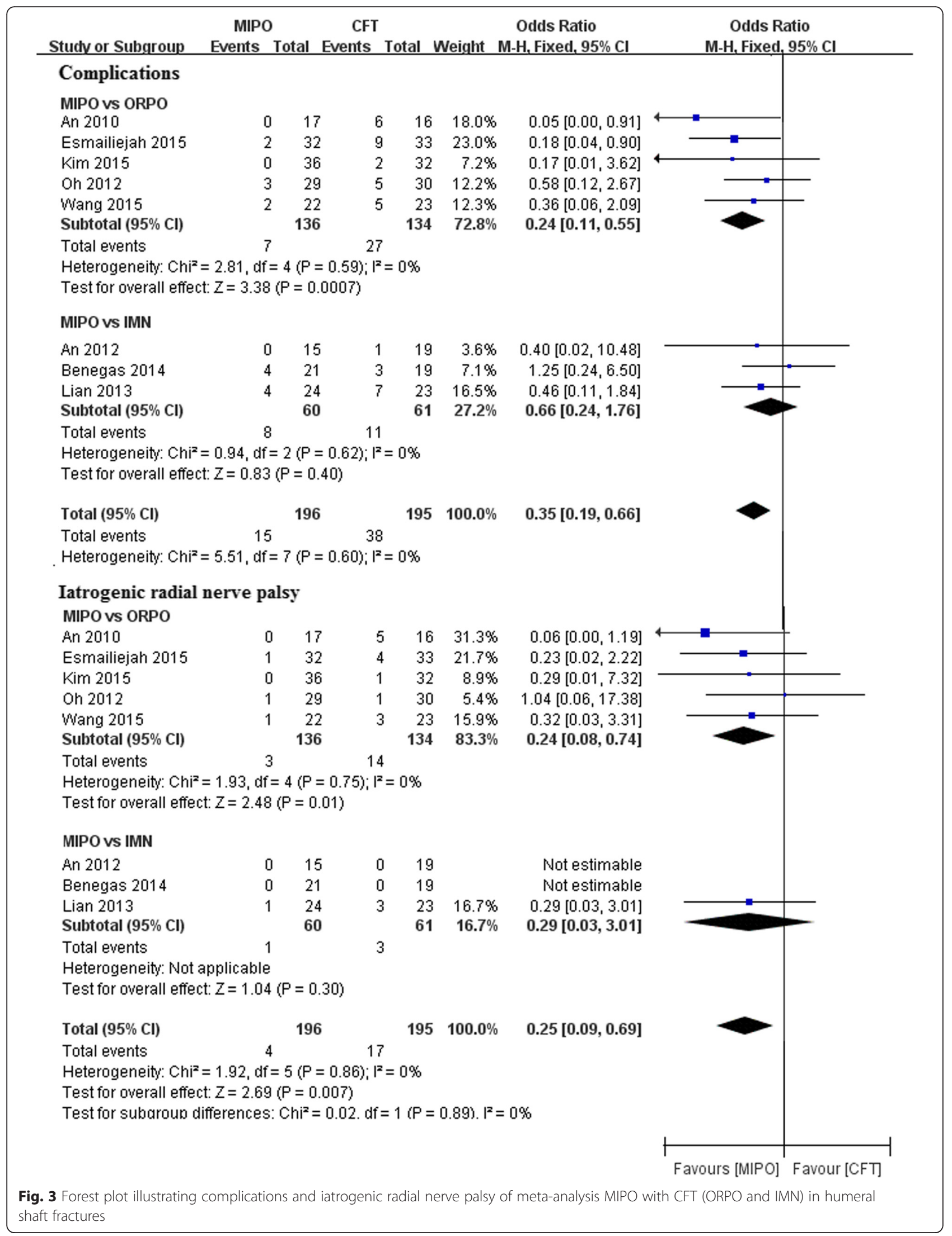




\begin{tabular}{|c|c|c|c|c|c|c|c|c|}
\hline Studv or Subgrou & \multicolumn{3}{|c|}{ MIPO } & $\begin{aligned} \mathrm{Cl} \\
\text { Events }\end{aligned}$ & CFT & Wieight $\mathrm{M}$ - & $\begin{array}{l}\text { Odds Ratio } \\
\text { l-H, Fixed, } 95 \% \mathrm{Cl}\end{array}$ & $\begin{array}{l}\text { Odds Ratio } \\
\text { M-H, Fixed, } 95 \% \mathrm{Cl}\end{array}$ \\
\hline \multicolumn{9}{|l|}{ Union rate } \\
\hline \multicolumn{9}{|l|}{ MIPQ VS ORPO } \\
\hline An 2010 & & 1 & 32 & & 33 & $54.3 \%$ & $0.23[0.02,2.22]$ & \\
\hline Kim 2015 & & 36 & 36 & 3 & 32 & $6.4 \%$ & $3.48[0.14,88.40]$ & \\
\hline \multicolumn{2}{|l|}{ Oh 2012} & 28 & 29 & 2 & 30 & $13.0 \%$ & $3.11[0.30,31.79]$ & \\
\hline \multicolumn{2}{|l|}{ Wang 2015} & 21 & 22 & 2 & 23 & $13.3 \%$ & $2.00[0.17,23.78]$ & \\
\hline \multicolumn{2}{|l|}{ Subt otal (95\% Cl) } & & 136 & & 134 & $87.1 \%$ & $1.17[0.40,3.45]$ & \\
\hline \multicolumn{2}{|c|}{ Total events } & 103 & & 9 & 19 & & & \\
\hline \multicolumn{9}{|c|}{ Heterageneity: Chi $^{2}=3.26, d f=3(P=0.35) ; I^{2}=8 \%$} \\
\hline \multicolumn{9}{|l|}{ MIPO vs IMN } \\
\hline Benegas 2014 & & 21 & 21 & 1 & 19 & $6.3 \%$ & $3.49[0.13,90.86]$ & \\
\hline Lian 2013 & & 23 & 23 & 2 & 23 & 6.79 & $3.13[0.12,81.00]$ & \\
\hline Subt otal $(95 \% \mathrm{C}$ & & & 59 & & 61 & $12.9 \%$ & $3.30[0.33,3.3 .05]$ & \\
\hline Total events & & 59 & & 5 & 9 & & & \\
\hline Test for overall effect: $Z=1.02(\mathrm{P}=0.31)$ & \multicolumn{8}{|c|}{ Heterageneity: Chi $^{2}=0.00, d f=1(P=0.96) ; I^{2}=0 \%$} \\
\hline Total ( $95 \% \mathrm{Cl})$ & & & 195 & & 195 & $100.0 \%$ & $1.45[0.55,3.78]$ & \\
\hline Total events & & 162 & & 15 & & & & \\
\hline $\begin{array}{l}\text { Heterageneity: } \\
\text { Test for overall e } \\
\text { Test for subarou }\end{array}$ & $\begin{array}{l}i^{2}=3.7 \\
\text { fect: } Z= \\
\text { differe }\end{array}$ & $\begin{array}{l}\text { 78, } \mathrm{df}= \\
=0.76 \\
\text { ences: }\end{array}$ & $\begin{array}{l}=5(\mathrm{P}= \\
\mathrm{P}=0.4 \\
\mathrm{Chi}^{2}=\end{array}$ & $\begin{array}{l}=0.58) ; \\
45) \\
0.64 . d\end{array}$ & $\begin{array}{l}F=0 \% \\
f=16 \mathrm{~F}\end{array}$ & $=0.42) \cdot F^{2}=0$ & & \\
\hline \multicolumn{9}{|c|}{ Fracture union time } \\
\hline \multicolumn{9}{|l|}{ MIPO vs ORPO } \\
\hline Esmailiejah 2015 & 17.14 & 3.21 & 32 & 21.43 & 8.57 & $10.8 \%$ & $-4.29[-7.42,-1.16]$ & \\
\hline Kim 2015 & 14.6 & 8.6 & 36 & 15.8 & 9.58 & $6.4 \%$ & $-1.20[-5.55,3.15]$ & \\
\hline Oh 2012 & 17.3 & 1.1 & 29 & 16.7 & 1.2 & $37.6 \%$ & $0.60[0.01,1.19]$ & - \\
\hline Subtotal $(95 \% \mathrm{Cl})$ & & & 114 & & & $11156.7 \%$ & $-1.91[-5.15,1.32]$ & \\
\hline \multicolumn{9}{|c|}{$\begin{array}{l}\text { Heterogeneity: } \text { Tau }^{2}=7.09 ; \mathrm{Chi}^{2}=11.88, \mathrm{df}=3(\mathrm{P}=0.008) ;\left.\right|^{2}=75 \% \\
\text { Test for overall effect: } Z=1.16(P=0.25)\end{array}$} \\
\hline \multicolumn{9}{|l|}{ MIPO vs IMN } \\
\hline Lian 2013 & 17.1 & 1.13 & 24 & 16.8 & 1.99 & $33.0 \%$ & $0.30[-0.63,1.23]$ & \\
\hline Subtotal $(95 \% \mathrm{Cl})$ & & & 39 & & & $42 \quad 43.3 \%$ & $0.36[-0.53,1.26]$ & \\
\hline \multicolumn{9}{|c|}{$\begin{array}{l}\text { Heterogeneity: } \text { Tau }^{2}=0.00 ; \mathrm{Chi}^{2}=0.22, \mathrm{df}=1(\mathrm{P}=0.64) ; \mathrm{I}^{2}=0 \% \\
\text { Test for owerall effect: } Z=0.79(\mathrm{P}=0.43)\end{array}$} \\
\hline & & & 153 & & & $153100.0 \%$ & $-0.22[-1.41,0.97]$ & \\
\hline $\begin{array}{l}\text { Heterogeneity: Tau } \\
\text { Test for overall effec } \\
\text { Test for subaroun d }\end{array}$ & $\begin{array}{l}0.90 ; \mathrm{Cl} \\
Z=0.36 \\
\text { ferences }\end{array}$ & $\begin{array}{l}\mathrm{Chi}^{2}=1 \\
6(\mathrm{P}=0 \\
\mathrm{s}: \mathrm{Chi}^{2}=\end{array}$ & $\begin{array}{l}2.10, \mathrm{df} \\
0.72) \\
=1.76 .0\end{array}$ & $d f=1(P$ & $=0.18$ ). & $\begin{array}{l}=59 \% \\
F^{2}=43.3 \%\end{array}$ & & \\
\hline
\end{tabular}




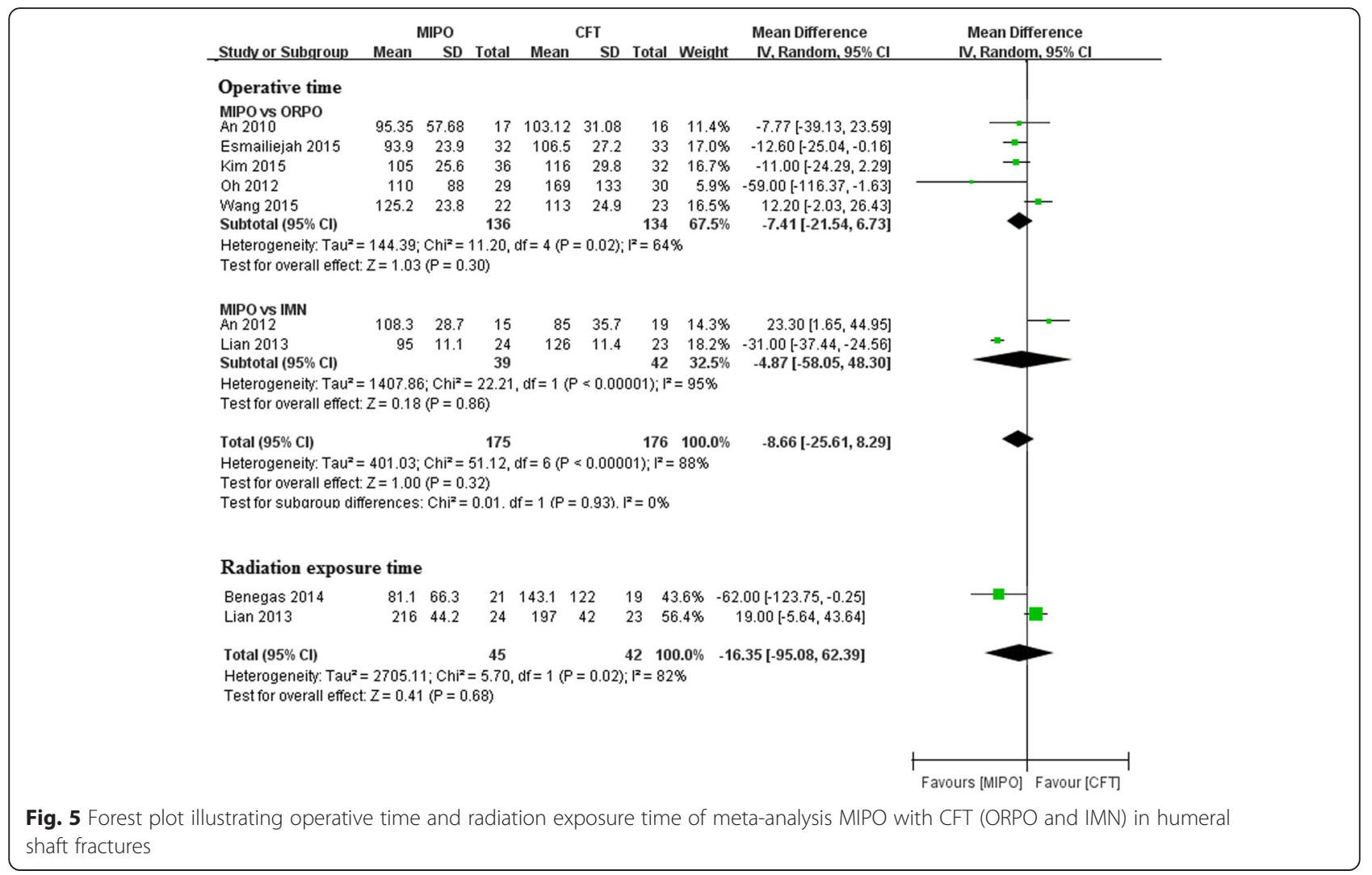

the optimal technique for humeral shaft fractures. Our meta-analysis did not detect any significant difference between MIPO and CFT (IMN and ORPO) in terms of operative time, fracture union rate, and fracture union time. In other words, compared with CFT, MIPO did not have the advantages of a higher fracture union rate or earlier union time.

Due to biomechanical characteristics and loadsharing capacity of the implant, IMN has achieved satisfying results in humeral shaft fractures. However, shoulder problems after IMN surgery also attract numerous orthopedic surgeons' attention $[5,28$, 29]. Injuries of the rotator cuff and impingement caused by prominent nail end are thought to be the main reasons for shoulder disfunction. Although subgroup analyses did not demonstrate any significant difference in the UCLA score between MIPO and IMN $(p=0.05)$, the result might be changed provided that the sample size was increased. Retrograde IMN approach is usually adopted to prevent shoulder problems. However, this benefit is obtained at the cost of supracondylar fracture and elbow problems [30].

Three papers in the IMN subgroup estimated the elbow function by the Broberg-Morrey score or MEPS. There was no significant difference in elbow function between IMN and MIPO in An or Benegas's studies $[20,26]$, where only antegrade IMN approach was used. Interestingly, in Lian's trial [19], where antegrade or retrograde IMN approach was applied, the MEPS in MIPO was significantly higher than that in IMN. In contrast, no significant difference was revealed in the UCLA score or MEPS between MIPO and ORPO.

Regarding the safety of therapies, the total complication rate of MIPO was $5.14 \%(7 / 136)$ while the total complication rate of ORPO was $20.15 \%$ (27/ 134 ) in the ORPO subgroup. Subgroup analyses detected a significant difference in the complication rate between MIPO and ORPO $(p<0.01)$. However, no significant difference was observed in the complication rate between MIPO and IMN. During the ORPO surgery, the radial nerve was dissected and the fracture site was exposed which resulted in disruption of periosteal blood supply. It was not surprising that the main complications reported in the ORPO subgroup were iatrogenic radial nerve palsy, nonunion, and infection.

Since injury of the radial nerve is a disastrous intraoperative complication in humeral shaft fractures, iatrogenic radial nerve palsy was evaluated separately in our meta-analysis. MIPO, as previously noted, has the advantage of no need for radial nerve exposure [15]. The total rate of iatrogenic radial nerve palsy in MIPO was $2.20 \%(3 / 136)$ in five studies, which was significantly lower than that in ORPO $(10.45 \%, 14 / 134, p=0.01)$. 
However, rich anatomical knowledge and long learning curve is required for MIPO. Otherwise, MIPO may lead to a high rate of radial nerve palsy or nonunion. Since the radial nerve was not dissected in IMN surgery either, subgroup analysis did not reveal any significant difference in iatrogenic radial nerve palsy between MIPO and $\operatorname{IMN}(p=0.30)$.

There are some limitations in this study. First of all, only eight articles covering 391 patients were included in this meta-analysis, of which only four were RCTs. This may weaken the strength of the evidence of this paper. Secondly, there were some confounding factors such as confirmation of complication. Pooling such data may lead to bias. At last, some baseline characteristics were different among the trials. There are various internal implants in the included studies, such as dynamic compression plate, locking compression plate, reamed IMN, or undreamed IMN. This may have potential effects on clinical and radiological outcomes.

\section{Conclusions}

In summary, based on the present evidence, MIPO is a better choice for treating humeral shaft fractures than CFT, though there is no significant difference between MIPO and CFT in terms of operative time, fracture union rate, and fracture union time. MIPO has a less rate of complications and iatrogenic radial nerve palsy than that of ORPO and higher adjacent joint function scores than those of IMN. However, more high-quality randomized trials are still needed to further confirm this conclusion in the future.

\section{Competing interests}

The authors declare that they have no competing interests.

\section{Authors' contributions}

$\mathrm{XQH}$ and SLG conceived and designed the experiments. $\mathrm{XQH}, \mathrm{SQX}$, and $\mathrm{HGL}$ performed the experiments. $\mathrm{XQH}, \mathrm{XZ}, \mathrm{BC}$, and $\mathrm{XJH}$ analyzed the data. JPD and ZWZ contributed the reagents/materials/analysis tools. XQH and SLG wrote the paper. All authors read and approved the final manuscript.

\section{Funding}

This work was supported by Jiaxing Science and Technology Bureau Foundation (Grant number: 2014AY21031-5)

\section{Author details \\ 'Department of Orthopaedics, the Second Affiliated Hospital of Jiaxing University, 1518 Huancheng North Road, Jiaxing, China. ${ }^{2}$ Department of Clinical Laboratory, the Second Affiliated Hospital of Jiaxing University, 1518 Huancheng North Road, Jiaxing, China.}

Received: 14 March 2016 Accepted: 4 May 2016

Published online: 11 May 2016

\section{References}

1. Ekholm R, Adami J, Tidermark J, Hansson K, Tornkvist H, Ponzer S. Fractures of the shaft of the humerus. An epidemiological study of 401 fractures. J Bone Joint Surg Br Vol. 2006;88(11):1469-73.
2. Strohm PC, Reising $K$, Hammer $T$, Sudkamp NP, Jaeger M, Schmal H. Humerus shaft fractures - where are we today? Acta Chir Orthop Traumatol Cechoslov. 2011;78(3):185-9.

3. Cole PA, Wijdicks CA. The operative treatment of diaphyseal humeral shaft fractures. Hand Clin. 2007;23(4):437-48. vi.

4. Tsai $\mathrm{CH}$, Fong $\mathrm{YC}$, Chen $\mathrm{YH}$, Hsu CJ, Chang CH, Hsu HC. The epidemiology of traumatic humeral shaft fractures in Taiwan. Int Orthop. 2009;33(2):463-7.

5. Walker M, Palumbo B, Badman B, Brooks J, Van Gelderen J, Mighell M. Humeral shaft fractures: a review. J Shoulder Elbow Surg. 2011;20(5):833-44.

6. Ekholm R, Tidermark J, Tornkvist H, Adami J, Ponzer S. Outcome after closed functional treatment of humeral shaft fractures. J Orthop Trauma. 2006; 20(9):591-6.

7. Koch PP, Gross DF, Gerber C. The results of functional (Sarmiento) bracing of humeral shaft fractures. J Shoulder Elbow Surg. 2002;11(2):143-50.

8. Zhao JG, Wang J, Wang C, Kan SL. Intramedullary nail versus plate fixation for humeral shaft fractures: a systematic review of overlapping metaanalyses. Medicine (Baltimore). 2015;94(11):e599.

9. Foster RJ, Dixon Jr GL, Bach AW, Appleyard RW, Green TM. Internal fixation of fractures and non-unions of the humeral shaft. Indications and results in a multi-center study. J Bone Joint Surg Am. 1985;67(6):857-64.

10. Jawa A, McCarty P, Doornberg J, Harris M, Ring D. Extra-articular distal-third diaphyseal fractures of the humerus. A comparison of functional bracing and plate fixation. J Bone Joint Surg Am. 2006;88(11):2343-7.

11. Ji F, Tong D, Tang H, Cai X, Zhang Q, Li J, et al. Minimally invasive percutaneous plate osteosynthesis (MIPPO) technique applied in the treatment of humeral shaft distal fractures through a lateral approach. Int Orthop. 2009;33(2):543-7.

12. Shin SJ, Sohn HS, Do NH. Minimally invasive plate osteosynthesis of humeral shaft fractures: a technique to aid fracture reduction and minimize complications. J Orthop Trauma. 2012;26(10):585-9.

13. Kobayashi M, Watanabe $Y$, Matsushita T. Early full range of shoulder and elbow motion is possible after minimally invasive plate osteosynthesis for humeral shaft fractures. J Orthop Trauma. 2010;24(4):212-6.

14. Lopez-Arevalo R, de Llano-Temboury AQ, Serrano-Montilla J, de LlanoGimenez EQ, Fernandez-Medina JM. Treatment of diaphyseal humeral fractures with the minimally invasive percutaneous plate (MIPPO) technique: a cadaveric study and clinical results. J Orthop Trauma. 2011; 25(5):294-9.

15. Zhiquan A, Bingfang Z, Yeming W, Chi Z, Peiyan H. Minimally invasive plating osteosynthesis (MIPO) of middle and distal third humeral shaft fractures. J Orthop Trauma. 2007;21(9):628-33.

16. Ellman H, Hanker $G$, Bayer M. Repair of the rotator cuff. End-result study of factors influencing reconstruction. J Bone Joint Surg Am. 1986;68(8):1136-44.

17. Morrey BF, Adams RA. Semiconstrained arthroplasty for the treatment of rheumatoid arthritis of the elbow. J Bone Joint Surg Am. 1992;74(4):479-90.

18. Ownby RL, Crocco E, Acevedo A, John V, Loewenstein D. Depression and risk for Alzheimer disease: systematic review, meta-analysis, and metaregression analysis. Arch Gen Psychiatry. 2006;63(5):530-8.

19. Lian K, Wang L, Lin D, Chen Z. Minimally invasive plating osteosynthesis for mid-distal third humeral shaft fractures. Orthopedics. 2013;36(8):e1025-1032.

20. Benegas E, Ferreira Neto AA, Gracitelli ME, Malavolta EA, Assuncao JH, Prada Fde $S$, et al. Shoulder function after surgical treatment of displaced fractures of the humeral shaft: a randomized trial comparing antegrade intramedullary nailing with minimally invasive plate osteosynthesis. J Shoulder Elbow Surg. 2014;23(6):767-74.

21. Kim JW, Oh CW, Byun YS, Kim JJ, Park KC. A prospective randomized study of operative treatment for noncomminuted humeral shaft fractures: conventional open plating versus minimal invasive plate osteosynthesis. J Orthop Trauma. 2015;29(4):189-94.

22. Esmailiejah AA, Abbasian MR, Safdari F, Ashoori K. Treatment of humeral shaft fractures: minimally invasive plate osteosynthesis versus open reduction and internal fixation. Trauma Mon. 2015;20(3):e26271.

23. Oh CW, Byun YS, Oh JK, Kim JJ, Jeon IH, Lee JH, et al. Plating of humeral shaft fractures: comparison of standard conventional plating versus minimally invasive plating. Orthop Traumatol Surg Res. 2012;98(1):54-60.

24. Wang C, Li J, Li Y, Dai G, Wang M. Is minimally invasive plating osteosynthesis for humeral shaft fracture advantageous compared with the conventional open technique? J Shoulder Elbow Surg. 2015;24(11):1741-8.

25. An Z, Zeng B, He X, Chen Q, Hu S. Plating osteosynthesis of mid-distal humeral shaft fractures: minimally invasive versus conventional open reduction technique. Int Orthop. 2010;34(1):131-5. 
26. An Z, He X, Jiang C, Zhang C. Treatment of middle third humeral shaft fractures: minimal invasive plate osteosynthesis versus expandable nailing. Eur J Orthop Surg Traumatol. 2011;22(3):193-9.

27. Gustilo RB, Anderson JT. Prevention of infection in the treatment of one thousand and twenty-five open fractures of long bones: retrospective and prospective analyses. J Bone Joint Surg Am. 1976;58(4):453-8.

28. Ajmal M, O'Sullivan M, McCabe J, Curtin W. Antegrade locked intramedullary nailing in humeral shaft fractures. Injury. 2001;32(9):692-4.

29. Baltov A, Mihail R, Dian E. Complications after interlocking intramedullary nailing of humeral shaft fractures. Injury. 2014;45 Suppl 1:S9-S15.

30. Loitz D, Konnecker H, Illgner A, Reilmann H. Retrograde intramedullary nailing of humeral fractures with new implants. Analysis of 120 consecutive cases. Unfallchirurg. 1998;101(7):543-50.

Submit your next manuscript to BioMed Central and we will help you at every step:

- We accept pre-submission inquiries

- Our selector tool helps you to find the most relevant journal

- We provide round the clock customer support

- Convenient online submission

- Thorough peer review

- Inclusion in PubMed and all major indexing services

- Maximum visibility for your research

Submit your manuscript at www.biomedcentral.com/submit
Biomed Central 